\title{
Mortalidade de jovens: análise do período de 1930 a 1991 (a transição epidemiológica para a violência)*
}

\section{Youth mortality: 1930-1991 period analysis (the epidemiological transition to violence)}

\author{
Letícia Legay Vermelho e Maria Helena P. de Mello Jorge \\ Departamento de Medicina Preventiva da Universidade Federal do Rio de Janeiro. Rio de Janeiro, RJ \\ - Brasil (L.L.V.), Departamento de Epidemiologia da Faculdade de Saúde Pública da Universidade de \\ São Paulo. São Paulo, SP - Brasil (M.H.P.M.J.)
}

\begin{abstract}
Resumo
Estudou-se a mortalidade de jovens ( 15 a 24 anos) das cidades do Rio de Janeiro e São Paulo, no período de 1930 a 1991, para avaliação das mudanças no perfil baseado em causas de morte. Os resultados mostraram que São Paulo experimentou um declínio rápido das taxas até 1970, assim como o Rio de Janeiro, até 1980. A partir daí a tendência é crescente, determinada pela mortalidade masculina. O Rio de Janeiro apresentou índices mais elevados durante todo o período. Durante a última década, o percentual de aumento foi mais elevado em São Paulo, aproximando as taxas. As doenças infecciosas, especialmente as tuberculoses, foram responsáveis pela mortalidade elevada, principalmente até a década de 50. Após 1960 a transição se tornou evidente e as causas violentas passaram a ocupar a primeira posição, principalmente acidentes de trânsito e homicídios. Doenças cardiovasculares, respiratórias e, mais tarde, a AIDS, também se destacaram.
\end{abstract}

Mortalidade, tendências. Adolescência. Violência, história.

\begin{abstract}
Youth (15 to 24 years old) mortality in the cities of Rio de Janeiro and S. Paulo from 1930 to 1991 is studied. The objective is the recovery of historical data covering the period from the third decade of this century up to the present so as to evaluate mortality profile changes based on causes of death and to compare them with international indicators. Results show that $S$. Paulo experienced a rapid decline in the death rate for the group up to 1970, as also happened in Rio de Janeiro city up to 1980. This latter city has always shown highter mortality rates. However, during the past decade a higher proportion of deaths
\end{abstract}

\footnotetext{
* Produto de Tese de Doutorado apresentada à Faculdade de Saúde Pública da USP, em 1995, sob o mesmo título.

Correspondência para/Correspondence to: Letícia Legay Vermelho - Núcleo de Estudos de Saúde Coletiva da Universidade Federal do Rio de Janeiro. Av. Brigadeiro Trompowsky, s/nº Hospital Universitário $5^{\circ}$ andar - Ilha do Fundão - 21941-590 Rio de Janeiro, RJ - Brasil.

Edição subvencionada pela FAPESP. Processo 95/2290-6.

Recebido em 25.9.1995. Reapresentado em 7.2.1996. Aprovado em 28.2.1996.
} 
occurred in S. Paulo resulting in closer mortality curves. Young people's mortality rates are not no longer decreasing. The rising tendency is accounted on male mortality increase. Infectious diseases, primarily tuberculosis, were responsible for the highest rates during the first decades studied, up to the fifties. After 1960 a transition took place and violent deaths, such as accidents and homicide, became the leading causes. Besides them, depending on the period analysed, cardiovascular diseases, respiratory infection and, later on, AIDS came to occupy a prominent position.

Mortality, trends. Adolescence. Violence, history.

\section{INTRODUÇÃO}

\section{O Jovem}

O conceito de juventude é função da época, do modo de inserção dos indivíduos em um determinado contexto social e do seu processo de aprendizagem. Ariès ${ }^{2}$, por exemplo, descreve o ritual de passagem da adolescência para a juventude, para o sexo masculino, na época da glória bélica romana, como "a idade da guerra ou da simulação - a idade da bravata". Duby ${ }^{10}$ põe em evidência a existência e o papel, na sociedade aristocrática do século XII, de uma categoria social particular, a dos jovens, definindo juventude como "a parte da existência compreendida entre < a vestidura e a paternidade>, que é "errante, vagabunda e violenta".

O Estatuto da Criança e do Adolescente do Brasil $^{6}$, considera criança, para os efeitos da lei, a pessoa até 12 anos de idade incompletos e, adolescente, aquela entre 12 e 18 anos. Já a Organização Mundial de Saú$\mathrm{de}^{31}$ preconiza que seja considerado adolescência o período que vai dos 10 aos 19 anos de idade e, juventude, aquele que transcorre entre os 15 e os 24 anos.

O termo adolescência denomina processo primariamente biológico que transcende a área psicossocial e que constitui período durante o qual se acelera o desenvolvimento cognitivo e a estruturação da personalidade. A juventude, por outro lado, é uma categoria fundamentalmente sociológica e se refere ao processo de preparação para que os indivíduos assumam o papel social do adulto, tanto do ponto de vista familiar, quanto profissional, com plenos direitos e responsabilidades ${ }^{29}$.

A delimitação desses períodos e seu pleno desenvolvimento variam conforme as oportunidades, tanto de educação quanto de incorporação efetiva à força de trabalho oferecidas e relacionadas às questões de classe, já que os níveis de integração biológicos, psicológicos e sociais são interdependentes e se desenvolvem interagindo ${ }^{18}$. A crescente importância dos adolescentes e jovens, como grupos, relaciona-se com as mudanças cada vez mais rápidas que se processam nos contextos social, econômico e cultural. Assim, o provimento de suportes adequados para que estas etapas da vida sejam de plena capacitação é pressuposto essencial ao desenvolvimento potencial da sociedade.

$\mathrm{O}$ alto ritmo de urbanização do País, o elevado processo de migração interna de jovens (no período 1980-1985 a população urbana de jovens crescia a taxas de 29,5 por mil habitantes, enquanto a população rural de jovens crescia a taxas de 5,5 por mil habitantes $)^{13,36}$, desenvolvendo cinturões de miséria e marginalidade na periferia das grandes cidades, associaram-se à baixa qualidade de vida, aquisição de doenças e produção de mortes.

Integrando este contexto adverso, as estratégias de sobrevivência assumidas pelos jovens tomam formas cada vez mais agressivas, como se esperaria, de acordo com as peculiaridades próprias da idade, o que irá contribuir decisivamente para o padrão mórbido que é observado no presente estudo.

\section{O Problema da Mortalidade}

Do ponto de vista da saúde e de todas as conseqüências sociais que lhe são inerentes, observa-se hoje que, na realidade, estes grupos vem se caracterizando pelo alto risco a que estão expostos. Estes se relacionam a comportamentos ou hábitos individuais/sociais, tais como fumar, beber, drogar-se, armarse assim como pelos contextos de miséria e violência a que os jovens estão submetidos.

Além disto, é o período de vida que se caracteriza pelo despertar da sexualidade que se apresenta muitas vezes para os jovens como sinônimo de doenças sexualmente transmissíveis, gravidez indesejada e aborto, que podem conduzir a situações extremamente graves tanto do ponto de vista da saú- 
de, quanto de inserção social, relatados em diversas partes do mundo ${ }^{1,14,16,17,21,30,35}$.

Às condições gerais que interferem na saúde de uma sociedade subdesenvolvida, como um todo, temos que adicionar para os jovens, hábitos e circunstâncias geradas a partir das necessidades próprias da idade, considerando-se sua localização geográfica, inserção social e cultural. Este somatório constitui um padrão próprio de saúde, que deverá ser sempre respeitado na medida em que se busquem, seriamente, soluções.

Barreto $^{3}$ sugere que é necessário não se tratar de forma generalizada e determinista a variabilidade das reações diferenciais às mudanças, evidenciadas pelos diferentes grupos e categorias sociais de uma dada população.

No momento em que visivelmente a sociedade brasileira sofre cada vez mais freqüentemente perdas de vidas de jovens, o presente trabalho propõese a resgatar o impacto dessas perdas e buscar elementos que possam sugerir as razões de tal retrocesso ao longo do tempo. As mortes de jovens devem ser consideradas, antes de tudo, perdas injustificadas, principalmente a partir da transição, que fez com que as sociedades modernas caminhassem rumo à longevidade tanto almejada.

Quando o óbito é o referencial do estudo, mais contundentes ficam esses perfis demográficos, históricos e sociais, pois a morte é o marco extremado da ruptura do ser humano com a sua experiência vivencial elementar que é a busca da sobrevivência, e isto é um fenômeno coletivo e um fato social.

Desta forma, para o Brasil, e em especial para os grupos de jovens, as mudanças demográficas associadas aos processos de industrialização e urbanização, o desenvolvimento tecnológico, as mudanças na estrutura produtiva, a crise econômica que se estende ao longo das décadas e se intensifica nos anos oitenta, a ampliação do mercado das drogas, assim como os novos estilos de vida ou formas de comportamento, configuram os padrões epidemiológicos que estão sendo analisados.

O objetivo do presente estudo é, pois, resgatar dados sobre mortalidade de jovens das capitais brasileiras, Rio de Janeiro (RJ) e São Paulo (SP), e comparar a magnitude da mortalidade do grupo jovem, segundo sexo e causas, no tempo e entre as capitais, situando, demográfica, histórica e socialmente, alguns dos resultados obtidos.

\section{MATERIAL E MÉTODO}

Foram coletados dados de óbitos e populações dos Municípios do Rio de Janeiro e São Paulo, das idades de 15 a 24 anos, nos anos de 1930, 40, 50, 60, 70, 80 e 91 . O grupo de 15 a 24 anos foi escolhido para análise por mesclar causas de morte com características diferentes, isto é, de adolescentes e de adultos jovens. As cidades foram escolhidas por sua importância demográfica, econômica e social, além de oferecerem disponibilidade de dados. Foram respeitados os limites geográficos vigentes em ambas as cidades e em cada um dos períodos.

Óbitos - Para o período de 1930 a 1991, foram coletados dados primários e secundários sobre óbitos geograficamente inseridos e oficialmente considerados como originários das capitais Rio de Janeiro e São Paulo. Os dados para a primeira cidade foram obtidos na Biblioteca do Arquivo Nacional, em relatórios publicados pela Secretaria de Estado de Saúde e através de relatórios do Ministério da Saúde, dependendo do período.

O Estado de São Paulo destaca-se por fornecer informações mais detalhadas sobre registros de mortalidade, tanto do ponto de vista de cobertura quanto de fidedignidade, a partir do início do século, já coletados e arquivados pelo então Departamento de Estatística do Estado de São Paulo, atual Fundação Sistema Estadual de Análise de Dados - FSEADE, de onde foram coletados os dados para a capital do Estado.

As causas de morte foram agrupadas e adaptadas da revisão da Classificação Internacional de Doenças, vigente naquele ano, para a $9^{\mathrm{a}}$ revisão, de $1975^{27}$, considerando-se os Capítulos para as mortes naturais e a Classificação Suplementar de Causas Externas para as mortes violentas, bem como, segundo a CID-Br ${ }^{25}$. Em cada década foram analisados os óbitos correspondentes ao ano em que houve a realização do recenseamento*, de forma a utilizar as respectivas populações para a construção de taxas mais acuradas. Como não houve censo em 1930, foi necessário estimá-lo. Para as estimativas e correções dos dados populacionais relacionados, foi utilizado o método geométrico.

As informações obtidas através das declarações de óbitos são, reconhecidamente, em inúmeros períodos, de baixa cobertura, pela não obediência à legislação específica. Se tem clareza, portanto, da pouca fidedignidade do produto obtido. Entretanto, é relevante a avaliação histórica de um perfil de mudanças em larga escala, o que é considerado no presente estudo, assim como a importância de suas causas.

Indicadores de saúde - Foram construídos coeficientes de mortalidade e mortalidade proporcional por sexo, específicos para o grupo de 15 a 24 anos e segundo causas básicas de morte pela $9^{\mathrm{a}}$ revisão da CID, para os Municípios do Rio de Janeiro e São Paulo, no período de 1930 a 1991. Os coeficientes, referentes às duas áreas, foram padronizados e comparados com outras áreas.

* Ministério da Agricultura, Indústria e Commércio. Directoria Geral de Estatística. Recenseamento do Brazil ( $1^{\circ}$ de setembro de 1920$)$. Rio de Janeiro,

1926 e 1928. Vol. IV, Tomos I e II

Fundação IBGE. Anuários Estatísticos e Censos Demográficos de 1940 a 1991. 
Análise documental - Documentos e notícias relatadas em jornais de época sobre as cidades estudadas foram resgatados na Biblioteca e Arquivo Nacional, localizados na cidade do Rio de Janeiro, sendo utilizados na análise histórica e social dos períodos estudados. Não é possível, entretanto, estabelecer relação direta entre essas informações e as mortes investigadas no presente estudo.

\section{RESULTADOS E COMENTÁRIOS}

\section{Evolução da Mortalidade dos Jovens no Tempo}

Os dados sobre a mortalidade proporcional para os jovens de São Paulo mostram que esta decresceu até 1960, permanecendo praticamente a mesma em 1970 quando, então, passou a se elevar, embora em níveis não muito acentuados, em relação aos óbitos de todas as idades. No Município do Rio de Janeiro, só estavam disponíveis os dados a partir de 1970. Mesmo assim eles permitiram confirmar que a mortalidade na faixa de 15 a 24 anos é baixa em relação às demais faixas etárias. Entretanto, nos últimos períodos ela já não vem declinando, o que se observava até 1950 pelos dados de São Paulo.

Observou-se que de 1930 a 1940 a mortalidade no Município do Rio de Janeiro é ainda crescente (coeficientes de 6,36 e 7,14 por mil habitantes respectivamente) (Figura 1), porém a partir daí ela decresce contínua e abruptamente até 1980 (1,78 por mil) quando, então, volta a elevar-se. $O$ coeficiente de mortalidade calculado para 1991 (2,45 por mil), é $61,5 \%$ menor do que o observado para 1930 . Entretanto, já entre 1980 e 1991, o aumento do coeficiente é de $37,6 \%$, muito mais acelerado do que qualquer valor observado para as décadas anteriores.

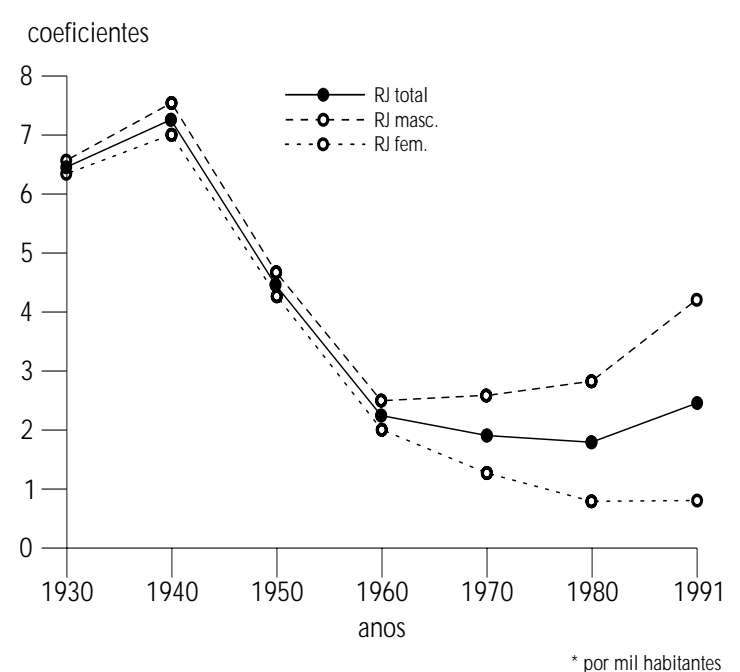

As taxas observadas para São Paulo, no período de 1930 a 1980 , que variam de 5,01 a 2,33 por mil (Figura 2) são sempre menores que os observados para o Rio de Janeiro, e a mortalidade é sempre decrescente até 1980 (1,45 por mil), com velocidade de queda maior até a metade do período, isto é, até 1960.

Mais precocemente que o Rio de Janeiro, cujo sentido do coeficiente se inverte somente a partir de 1980, já em 1970 São Paulo apresenta leve aumento. Ao final do período estudado observa-se que esta cidade apresenta níveis 53,5\% menores do que em 1930. A mortalidade no último ano analisado é praticamente igual nas duas áreas. Considerando-se que esses dados dizem respeito à uma população cuja expectativa é de que nela ocorram poucos óbitos, a análise da mortalidade por sexo e causas de morte pode mostrar os determinantes desta tendência a qual contraria as expectativas.

Os valores das taxas para ambas as capitais, em 1991, são maiores que os observados para outros países das Américas ${ }^{31}$, tais como Chile (1987) de 0,8 por mil; Costa Rica (1988) de 0,6 por mil e Estados Unidos (1987) de 1,0 por mil; semelhantes à Guatemala (1984) de 2,1 por mil e menores que as Ilhas Malvinas (1983), ano da guerra, de 4,9 por mil.

Ao lado dos transformações sociais e avanços tecnológicos na área da medicina, que estão relacionados às quedas da mortalidade em geral, é necessário buscar outros elementos que têm relação mais direta com a mortalidade nesta faixa, como qualidade de vida e aspectos da cultura e do comportamento, que são abordados adiante.

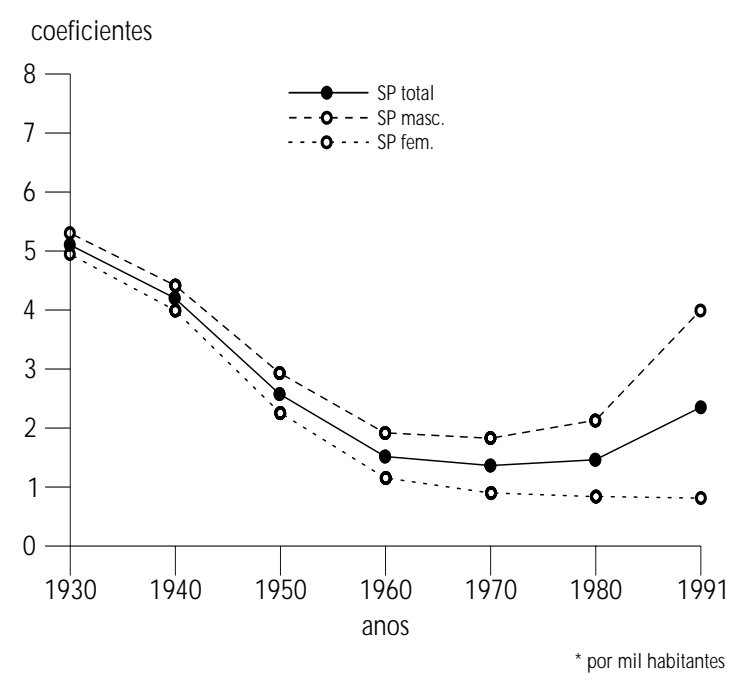

Figuras 1 e 2 - Coeficientes de mortalidade* segundo sexo, faixa etária de 15 a 24 anos, Municípios do Rio de Janeiro e São Paulo, 1930-1991. 


\section{Mortalidade segundo Sexo e Idade}

Em torno dos 15 anos de idade, o diferencial por sexo da mortalidade começa a se apresentar com maior intensidade, assim o estudo das variações da mortalidade separadamente para cada sexo é necessário, como já era observado por Graunt desde $1662^{15}$.

O coeficiente por todas as causas, para o sexo masculino, tanto no Rio de Janeiro quanto em São Paulo, acompanha o declínio da mortalidade para ambos os sexos, porém a partir daí passa a se elevar, principalmente na década $1980-90(48,6 \%$ e $87,6 \%)$ (Figuras 1 e 2).

Embora os valores das taxas sejam maiores para o Rio de Janeiro (variam de 6,4 a 4,16 por mil, de 1930 a 1991), a mudança do perfil de causas de morte ocorreu mais precocemente em São Paulo, assim como o aumento proporcional da última década é praticamente o dobro para a última capital. Se esta tendência se mantiver, São Paulo poderá vir a atingir os valores observados para o Rio de Janeiro e superar os valores observados para 1930.

De toda maneira, o jovem do sexo masculino vem perdendo rapidamente os ganhos obtidos sobre a mortalidade ao longo do período, sendo que de 1930 a 1991 a mortalidade em São Paulo declinou, na realidade, somente $24,5 \%$, graças em parte, à subida vertiginosa ocorrida na última década. No Rio de Janeiro, o declínio foi de 43,9\% do ano de 1940 (maior coeficiente) até 1991.

Para o sexo feminino, a mortalidade declinou de forma constante e chega a um valor, em 1991, em torno de sete vezes menor do que o de 1930 (as taxas variam de 6,25 a 0,81 por mil (RJ) e de 4,84 a 0,79 por mil (SP), sendo que os níveis de 1991 se mantêm os mesmos de 1980. A relação dos coeficientes, em 1991, entre homens e mulheres é de 5,1: 1 (RJ) e $4,9: 1$ (SP). De 1930 a 1960 esta relação foi de praticamente $1: 1$.

Para a mulher jovem ocorreu uma profunda mudança positiva no perfil de sua mortalidade. Isto significa que, se na terceira década do século homens e mulheres se achavam em condições semelhantes quanto à mortalidade, hoje estão em situação oposta. Entretanto, comparando-se com os resultados citados em estudo sobre mulheres em idade fértil ( $15 \mathrm{a}$ 44 anos) (dados de 1986) ${ }^{16}$, as jovens de 15 a 24 anos apresentaram maiores coeficientes de mortalidade por todas as causas.

Estes valores e as variações entre os sexos podem ser comparadas com os coeficientes por todas as causas e por mil habitantes, de outros países da América Latina e Caribe ${ }^{28,31}$. O Rio de Janeiro, nos anos de 1980 e 1991, apresenta valores para o sexo masculino dos mais elevados $(2,8$ e 4,2$)$ dentre os países de maior coeficiente registrado, tais como Argentina (1986), 1,2; Venezuela (1987), 1,6; México (1986), 1,8; Equador (1987), 1,6; Guatemala (1984), 2,5; Colômbia (1984), 2,1. Os valores dos coeficientes para o Rio de Janeiro são menores, somente, do que El Salvador (1984), 5,1 e as Ilhas Malvinas (1983), 9,6, em situações de guerra.

São Paulo, por outro lado, apresenta coeficientes para os jovens do sexo masculino, por mil habitantes, em 1980, de 2,0, e em 1991, de 3,9, superiores ao da Argentina (1986) e do Chile (1987), ambos com valores de 1,2, Estados Unidos (1987), de 1,4, entre ou$\operatorname{tros}^{31}$. No sexo feminino, os dois municípios, apresentaram valores para a mortalidade por mil habitantes, em 1980 e 1991, de 0,8, tanto no Rio de Janeiro quanto em São Paulo, valores inferiores aos de El Salvador (1984), 1,2 e Equador (1987), 1,0; semelhantes aos da Colômbia (1984), 0,8 e superiores aos da Argentina (1986), 0,6; México (1986), 0,7; Chile (1987), 0,5 e Estados Unidos (1987), 0,5, entre outros ${ }^{31}$. Concluise que também para o sexo feminino, as duas capitais não demonstraram situação vantajosa.

Quanto às variações entre os sexos, elas são semelhantes às observadas naqueles países, chegando neles a ser duas a três vezes maiores. Mesmo assim, o Rio de Janeiro superou estas taxas, exibindo, em 1980, uma relação masculino/feminino de 3,5:1, que em 1991 é ainda maior.

Somente Cuba, dentre os países que fornecem tais informações, exibe valores de $1,2: 1$, bastante próximos para os sexos, observando-se até uma pequena tendência de aumento entre as mulheres a partir de $1972^{32}$

\section{Mortalidade segundo Causas}

As tabelas 1 e 2 mostram que tanto em São Paulo quanto no Rio de Janeiro as doenças infecciosas e parasitárias (DIP) ocuparam o primeiro lugar até 1960, quando cederam lugar às causas externas (causas violentas acidentais e intencionais).

O grupo das tuberculoses esteve sempre em destaque. As taxas de mortalidade por DIP, nas duas cidades, decresceram ao longo do período 1930-91, em quase $100 \%$. Apesar da queda da mortalidade por essas causas já vir sendo registrada ${ }^{26} \mathrm{e}$, em geral, depender das melhorias das condições gerais de vida dos indivíduos, o impacto das tecnologias médicas curativas com o advento dos antibióticos e, preventivas, principalmente vacinas e quimioprofiláticos, sobretudo a partir de 1940, sobre este grupo de doenças, é acelerado e evidente em todo o período. 
Tabela 1 - Posição dos coeficientes de mortalidade*, faixa etária de 15 a 24 anos, Município do Rio de Janeiro, 1930-1991.

\begin{tabular}{cccccccc}
\hline Posições & 1930 & 1940 & 1950 & 1960 & 1970 & 1980 & 1991 \\
\hline Primeira & DIP & DIP & DIP & Causas ext. & Causas ext. & Causas ext. & Causas ext. \\
& 423,4 & 409,7 & 239,6 & 93,6 & 101,6 & 120,6 & 185,1 \\
\hline Segunda & D. Ap. Resp. & Causas ext. & Causas ext. & DIP & D. Ap. Circ. & D. Ap. Circ. & D. Glând. \\
& 51,6 & 79,6 & 68,0 & 57,0 & 20,4 & 11,8 & 7,8 \\
\hline Terceira & Causas ext. & D. Ap. Resp. & D. Ap. Circ. & D. Ap. Circ. & DIP & Neoplasm. & DIP* \\
& 40,0 & 64,7 & 36,4 & 30,6 & 15,4 & 8,2 & 7,1 \\
\hline Quarta & D. Ap. Genit. & D. Ap. Circ. & D. Ap. Resp. & Neoplasm. & N eoplasm. & D. Ap. Resp. D. Ap. Circ.* \\
& 25,2 & 43,3 & 23,8 & 11,8 & 12,2 & 6,1 & 7,1 \\
\hline Quinta & D. Ap. Circ. & D. Ap. Dig. & D. Ap. Dig. & D. Ap. Resp. D. Ap. Resp. DIP/D. Ap. C. D. Ap. Resp* \\
& 24,8 & 25,3 & 9,4 & 8,9 & 8,6 & 4,6 & 7,1 \\
\hline
\end{tabular}

* por cem mil habitantes

O bs:: N ão foram considerados os capítulos dos Sintomas, Sinais e Afecções maldefinidas e das Complicações da Gravidez, do Parto e do Puerpério.

Tabela 2 - Posição dos coeficientes de mortalidade*, faixa etária de 15 a 24 anos, Município de São Paulo, 1930-1991.

\begin{tabular}{cccccccc}
\hline Posições & 1930 & 1940 & 1950 & 1960 & 1970 & 1980 & 1991 \\
\hline Primeira & DIP & DIP & DIP & Causas ext. & Causas ext. & Causas ext. & Causas ext. \\
& 234,7 & 211,6 & 91,3 & 50,5 & 69,5 & 92,3 & 170,7 \\
\hline Segunda & Causas ext. & Causas ext. & Causas ext. & DIP & D. Ap. Circ. & D. Ap. Circ. & D. Glând. \\
& 58,2 & 54,5 & 53,4 & 23,9 & 11,9 & 10,1 & 17,0 \\
\hline Terceira & D. Ap. Resp. & D. Ap. Resp. & D. Ap. Circ. & D. Ap. Circ. & DIP & D. Ap. Resp. D. Ap. Resp. \\
& 49,8 & 36,6 & 34,5 & 20,4 & 9,1 & 9,6 & 8,7 \\
\hline \multirow{2}{*}{ Quarta } & D. Ap. Circ. & D. Ap. Circ. & Neoplasm. & Neoplasm. & Neoplasm. & Neoplasm. & D. Ap. Circ.* \\
& 30,6 & 31,2 & 11,8 & 13,1 & 7,7 & 7,3 & 8,3 \\
\hline Quinta & D. Ap. Dig. & D. Ap. Dig. & D. Ap. Resp. & D. Ap. Resp. D. Ap. Resp. & DIP & Neoplasm. \\
& 26,6 & 17,6 & 9,7 & 9,5 & 6,9 & 5,3 & 7,6 \\
\hline
\end{tabular}

* por cem mil habitantes

O bs.: Não foram considerados os capítulos dos Sintomas, Sinais e Afecções maldefinidas e das Complicações da Gravidez, do Parto e do Puerpério.

As causas externas, ao longo do tempo, sempre estiveram entre as principais causas de morte na faixa etária estudada, quase sempre na segunda posição em ambas as capitais, embora com coeficientes baixos. Enquanto as DIP declinaram no tempo, as causas externas ascenderam, ocupando, em 1960, a primeira posição, tanto no Rio de Janeiro quanto em São Paulo. Os coeficientes de mortalidade específicos por causas externas, para ambos os sexos, sofreram um acréscimo de 362,8\% (RJ) e de 193,3\% (SP), de 1930 a 1991. Dentre essas causas foram os acidentes de transporte e os homicídios que se destacaram, dependendo do período analisado.

Estes valores são bem mais elevados que os observados por Mello Jorge ${ }^{23}$, para os adolescentes no Brasil (dados de 1986). As taxas para o mesmo grupo em Cuba (44,7 por cem mil habitantes) no mesmo ano, Estados Unidos $(44,6)$ e outros países latino-americanos como a Argentina $(29,8)$, também são menores do que os achados para os jovens no presente estudo.
Além das DIP e as causas externas, outros grupos que permaneceram entre os cinco primeiros, por todo o período, foram as doenças do aparelho circulatório e do aparelho respiratório. Também entre os principais, as doenças do aparelho digestivo e geniturinário não apareceram todos os anos (Tabelas 1 e 2), pois foram cedendo lugar aos neoplasmas. Estes, por sua vez, no Rio de Janeiro, foram superados pelas doenças das glândulas endócrinas, da nutrição e do metabolismo e transtornos imunitários, o que em São Paulo ocorreu com as DIP.

Quanto ao posicionamento destes outros grupos, que não as DIP e as causas externas, para o sexo masculino, no Rio de Janeiro, enquanto as DIP ocuparam a primeira posição, as outras causas eram mais evidentes; na medida em que este lugar foi sendo ocupado pelas causas externas, a proporção de óbitos atribuída a elas ficou cada vez menor. Tal não ocorreu com o sexo feminino, no qual as outras causas ampliaram sua participação. 
Para São Paulo, no sexo masculino, observou-se padrão semelhante ao Rio de Janeiro, cabendo destacar a contribuição evidente do grupo das doenças das glândulas endócrinas, da nutrição e do metabolismo e transtornos imunitários, na mortalidade dos jovens em 1991. No sexo feminino, apesar da semelhança com o padrão exibido pela mortalidade proporcional no Rio de Janeiro, para o mesmo sexo, o posicionamento do último grupo mencionado, em 1991, foi ainda mais importante do que no sexo masculino, provavelmente porque nele as causas externas são por demais "competitivas".

\section{Resumindo:}

\section{$1^{\circ}$ - Com Relação aos Coeficientes de Mortalidade}

\section{No Rio de Janeiro}

- Passaram de 6,36 para 2,45 por mil habitantes (queda de $61,5 \%$ no período).

\section{Em São Paulo}

- Passaram de 5,01 para 2,33 por mil habitantes (queda de 55,5\% no período).

- Os coeficientes foram sempre maiores no Rio de Janeiro do que em São Paulo.

\section{$2^{\circ}$ - Com Relação ao Sexo}

- Os coeficientes foram decrescentes em ambos os sexos, com exceção do sexo masculino, de 1980 a 1991, que em ambas as cidades se elevou.

- Os coeficientes do sexo masculino foram sempre maiores do que os do sexo feminino em ambas as capitais (a relação foi sempre crescente e variou entre $1: 1$ e 5,1: 1 no Rio de Janeiro e $1,1: 1$ e 4,9: 1 em São Paulo).

\section{$3^{\circ}$ - Relativo às Causas}

- As doenças infecciosas e parasitárias apresentaram os coeficientes mais elevados nos dois municípios até 1950, sendo que os do Rio de Janeiro foram sempre maiores do que os de São Paulo. Do ano de 1930 a 1991, permaneceram entre os cinco principais grupos de causas de morte, no Rio de Janeiro, e em São Paulo, de 1930 a 1980.

- Dentre as doenças infecciosas e parasitárias ressalta-se a importância das tuberculoses que, até 1950, apresentaram coeficientes muito elevados no Rio de Janeiro e em São Paulo. Outras causas registradas foram doenças infecciosas intestinais, doenças venéreas e, embora com coeficientes muito baixos, doenças meningo- cócica, poliomielite aguda, varíola e malária.

- As causas externas que nos primeiros anos ocupavam a segunda e terceira posições, nas duas capitais, a partir de 1960 passaram para o primeiro posto, com coeficientes elevados e crescentes. No período elevaram-se de 40,0 para 185,1 por cem mil habitantes no Rio de Janeiro e de 58,2 para 170,7 por cem mil habitantes, em São Paulo, mostrando aumentos respectivos de $362,8 \%$ e $193,3 \%$. Esses aumentos foram maiores no sexo masculino, onde os coeficientes são ainda mais elevados.

- Os tipos de causas externas mais freqüentes foram os acidentes de trânsito, que mostraram seus maiores coeficientes em 1970 no Rio de Janeiro e em 1991 em São Paulo e os homicídios, que apresentaram seus maiores coeficientes em 1991, para o Rio de Janeiro e São Paulo. Entretanto considera-se aí uma subenumeração importante, principalmente para o Rio de Janeiro. Os coeficientes por violências apresentaram ampla variação entre os sexos masculino e feminino, chegando a mostrar, no caso dos homicídios, uma relação de 22 : 1e $16: 1$, respectivamente no Rio de Janeiro e São Paulo.

- O aumento relativo observado para o conjunto das violências em São Paulo, no último período, deve ser considerado.

- Além das doenças infecciosas e parasitárias e causas externas, estiveram entre as cinco primeiras causas de morte, as doenças do aparelho circulatório, respiratório, digestivo, geniturinário, neoplasmas e doenças das glândulas endócrinas, da nutrição e do metabolismo e transtornos imunitários, dependendo do período considerado.

- As doenças do aparelho circulatório, embora decrescentes, passaram a ocupar posições mais elevadas com as quedas acentuadas das doenças infecciosas e parasitárias. Destacou-se o grupo da febre reumática e doenças reumáticas do coração, cujos coeficientes foram, em geral, mais elevados no sexo feminino.

- As doenças do aparelho respiratório apresentaram também coeficientes decrescentes, sendo que determinadas categorias, como as pneumonias, apresentaram taxas elevadas até 1940 , em ambos os municípios.

- As neoplasias começaram a aparecer entre os cinco primeiros grupos, respectivamente, em 1950, em São Paulo e, em 1960, no Rio de Janeiro. As leucemias se destacaram, embora com coeficientes muito baixos, o que está de acordo 
com o comportamento das doenças crônicodegenerativas, que nesta faixa de idade são pouco freqüentes.

- As causas maternas, embora não se destacassem ao longo do período, em termos de frequiência, apareceram nos primeiros anos e também declinaram. Na realidade, não deveriam sequer aparecer por seu caráter de previnibilidade.

- As doenças das glândulas endócrinas, da nutrição e do metabolismo e transtornos imunitários apareceram como segundo grupo mais importante em 1991, nas duas cidades. Este fato se deve, provavelmente, ao aparecimento da AIDS no início da década de 80. Os aumentos dos coeficientes se deram, principalmente, às custas dos aumentos verificados no sexo masculino.

\section{CONSIDERAÇÕES FINAIS}

O estudo se propõe recuperar informações sobre a mortalidade de jovens a partir do ano de 1930. Esse ano foi decisivo quanto às transformações políticas da maior importância e, ao mesmo tempo, às mudanças fundamentais e profundas na estrutura econômica do País. É nesse período que as atividades industriais são concentradas em torno do eixo São Paulo-Rio de Janeiro. Após 1930 ocorre a redução abrupta da entrada de imigrantes europeus e o intensivo processo de migração interna para São Paulo ${ }^{20}$.

Citam-se também as melhorias do saneamento básico e, a partir daí, os progressos da medicina internacional, o desenvolvimento de inseticidas e o avanço das políticas de saúde e seus impactos principalmente sobre as doenças mais prevalecentes nesse período, as DIP. Expande-se então a industrialização e, principalmente em São Paulo ocorre um decréscimo muito rápido da mortalidade infantil. Segundo Sawyer ${ }^{33}$, o crescimento urbano e a ascensão econômica dos trabalhadores, a exemplo de São Paulo na fase agrário-exportadora (1850 a 1929), envolveu aparentemente declínio significativo dos níveis de mortalidade nos adultos e também de crianças em relação aos níveis observados para o período anterior (escravocrata-colonial), embora a mortalidade fosse elevada, quando comparada à fase de substituição de importação (1930 a 1956).

Surgem nesse período as idéias sobre a relação entre desenvolvimento econômico e saúde. Seria possível, para os países subdesenvolvidos, elevar seu padrão de saúde e se desenvolverem a partir da importação das novas técnicas científicas, o que veio, em parte, acontecer com a saúde, no que diz respeito às quedas da mortalidade, como descrito mais adiante, porém não com a saúde, quando se considera a qualidade de vida global de uma sociedade.

Durante a década de 40, a grande migração urbana ${ }^{19}$ atesta a perda de importância das atividades agrícolas e provoca o êxodo da população rural. Bilac ${ }^{4}$ descreve a grande expansão populacional nas capitais, durante o decênio 40-50 em São Paulo.

O período juscelinista (1956-1960), período de transição da fase de substituição de importações para a industrialização pesada, que prometia construir cinqüenta anos em cinco, expandiu o parque industrial, principalmente em São Paulo, em função do ciclo de investimento nos países do Terceiro Mundo ${ }^{20}$. A partir da internacionalização da economia definem-se novos padrões de acumulação, a industrialização determina um novo modelo de estado essencialmente urbano, subordinando outros setores da economia. A força de trabalho técnica de indústria, de serviços e burocrática em expansão, obteve salários que permitiram padrão de vida relativamente elevado, como já foi citado?.

Na realidade, ao final da fase agrário-exportadora, a taxa de mortalidade infantil, mesmo em São Paulo, apresentava níveis tão elevados quanto os da Inglaterra no começo do século XVIII, embora já houvesse, no mundo, alta tecnologia para evitá-la ${ }^{22}$.

Depois de uma expansão violenta, o capitalismo diminuiu sua produção e, conseqüentemente, aumentou o desemprego, que cada vez mais atingiu populações mais jovens. A partir de 1964, no período denominado "capitalismo dependente-associado", passa a predominar uma ideologia modernizadora, porém extremamente conservadora e autoritária com elevada contenção de salários e concentração de renda. Nesse período, a taxa de mortalidade infantil volta a se elevar, com aumento dos casos de óbitos por DIP. Yunes ${ }^{38}$, estudando os níveis de saúde na região da Grande São Paulo, relata acréscimos nas taxas de mortalidade infantil no período de 1961 e 1967, tanto para o Município, quanto para o Estado de São Paulo.

De 1968 a 1973 ocorre o denominado "milagre econômico" e uma retomada do crescimento. A partir de meados da década de 70, a crise econômica se instala no País, se intensifica e se estende por toda a década de 80 . Yasaki ${ }^{37}$ associa o acréscimo das taxas de mortalidade na faixa etária de 1 a 4 anos, no início da década de 70, na Região Metropolitana de São Paulo, com a redução do salário mínimo real e o rápido processo de metropolização e urbanização com o elevado número de migrantes chegados à capital. Este processo irá se reverter a partir de 1975, com a 
expansão da estrutura da rede de saúde e saneamento ${ }^{37}$. Entretanto, a também ascendente mortalidade dos jovens do sexo masculino, não irá mais declinar, efeito da crise econômica e de seus efeitos recessivos.

Minayo e Souza ${ }^{24}$ mostram o aprofundamento da crise econômica na década de 80 , para a cidade do Rio de Janeiro, com o mercado de trabalho formal recessivo e a ampliação do mercado paralelo que principalmente para os jovens, significou o mercado das drogas.

Por um lado, o desenvolvimento tecnológico acelerado permitiu o acesso a bens de consumo por uma parcela maior da população e, por outro, produziu bolsões de miséria, em que o desemprego e o subemprego são constantes, afetando principalmente os jovens ${ }^{13}$. Estes já se constituem em população, até mesmo considerada, "desnecessária ou supérflua", excluída de qualquer projeto nacional ou do acesso aos bens produzidos. Como cita Zaluar ${ }^{39}$, "o desemprego e o subemprego que mais afetam os jovens não seriam suficientes para explicar a adesão aos valores da subcultura criminosa. É que a saída criminosa é a entrada possível para a sociedade de consumo já instalada no País".

O perfil epidemiológico mostrado pelas causas de morte é de importância inconteste, sendo também, como cita Breilh7, "expressão do perfil reprodutivo social da classe". Tal perfil não se configura para um determinado país, estado ou cidade, mas sim para qualquer sociedade em que haja indivíduos vivendo sob condições semelhantes, favoráveis ou adversas, em qualquer período histórico.

O presente estudo evidenciou que a queda da mortalidade ao longo do século atual, entre os jovens, não persistiu nas últimas décadas. A maior velocidade de declínio foi verificada até 1960 . Na análise das causas que determinaram o padrão de mortalidade dos jovens, ao longo do período, as DIP delinearam o perfil declinante até então, sendo substituídas pelas causas externas, invertendo a tendência da curva de mortalidade, cuja maior inflexão é exibida a partir de 1980 (Figuras 3 e 4).

Esta mudança ocorreu, na realidade, às custas do aumento da mortalidade no sexo masculino (Figuras 5 e 7). Para o sexo feminino (Figuras 6 e 8), os níveis mantiveram-se constantes sendo que a relação entre os óbitos masculinos e femininos por causas externas chega a 9,7:1 para o Rio de Janeiro e 9,4: 1 para São Paulo, em 1991. Assim, para a jovem dessas capitais, a substituição do padrão epidemiológico através da grande diminuição das mortes por DIP, que determinou quedas drásticas dos coeficientes de mortalidade por todas as causas, significou ganho de anos de vida potenciais, que persistem. Entretanto, para o sexo masculino a transição não se deu da mesma forma. As grandes epidemias de DIP foram ao longo do tempo sendo substituídas por outra, a de violências.

Enquanto as DIP predominaram, destacaram-se as tuberculoses, sendo elas responsáveis, principalmente até 1960, no Rio de Janeiro, e 1950 em São Paulo, pela grande maioria dos óbitos do grupo. A elevada mortalidade por tuberculose, durante as primeiras décadas do século XX, era decorrente, entre outros, do fato de não ser identificada como transmissível, não atingindo indiscriminadamente qualquer classe social, não representar séria ameaça às relações de produção vigentes, e em especial às relações do comércio exterior, não interessando aos planejadores e executores das políticas públicas, ${ }^{5,8}$. Além destas, outras questões, da mesma forma abrangentes, permeiam a história da tuberculose dentro da estrutura social das cidades estudadas.

O perfil de mortalidade que é observado em 1930 mostra exatamente a magnitude que a tuberculose toma como produtora de mortes, em comparação com outras DIP que já não se destacavam, embora exibissem habitualmente maior mortalidade. Esta dimensão não é a mesma para as duas cidades. As DIP apresentaram declínio mais homogêneo na cidade de São Paulo. A tuberculose, no Rio de Janeiro, apresentava níveis mais elevados e ainda persistentes nas duas primeiras décadas abrangidas pelo estudo.

Engel ${ }^{11}$, ao comentar a produção científica dos médicos do período de 1845 a 1890, refere-se ao Rio de Janeiro como "uma cidade doente, que, a medida que crescia social, econômica e espacialmente, mais sofria com a precariedade das condições de higiene pública".

A urbanização e o processo de modernização pelo qual passou a cidade, então Capital Federal, antes das campanhas sanitárias, foram feitos através de desapropriações e demolições, atingindo diretamente a população pobre e crescente da cidade ${ }^{8,34}$. Obras e atividades especulativas impediram o aproveitamento das oportunidades de industrialização. O modelo de distribuição populacional no Rio de Janeiro, na realidade, já se delineara no final do século passado. As reformas da cidade expulsaram milhares de trabalhadores para terrenos baldios em morros vizinhos, originando as favelas.

As instituições dirigentes de São Paulo, interessadas em ajudar o setor privado a favor de seus interesses, aproveitou a farta mão-de-obra barata, originária da abolição da escravatura, e espalhou a população trabalhadora para loteamentos nas regiões pe- 

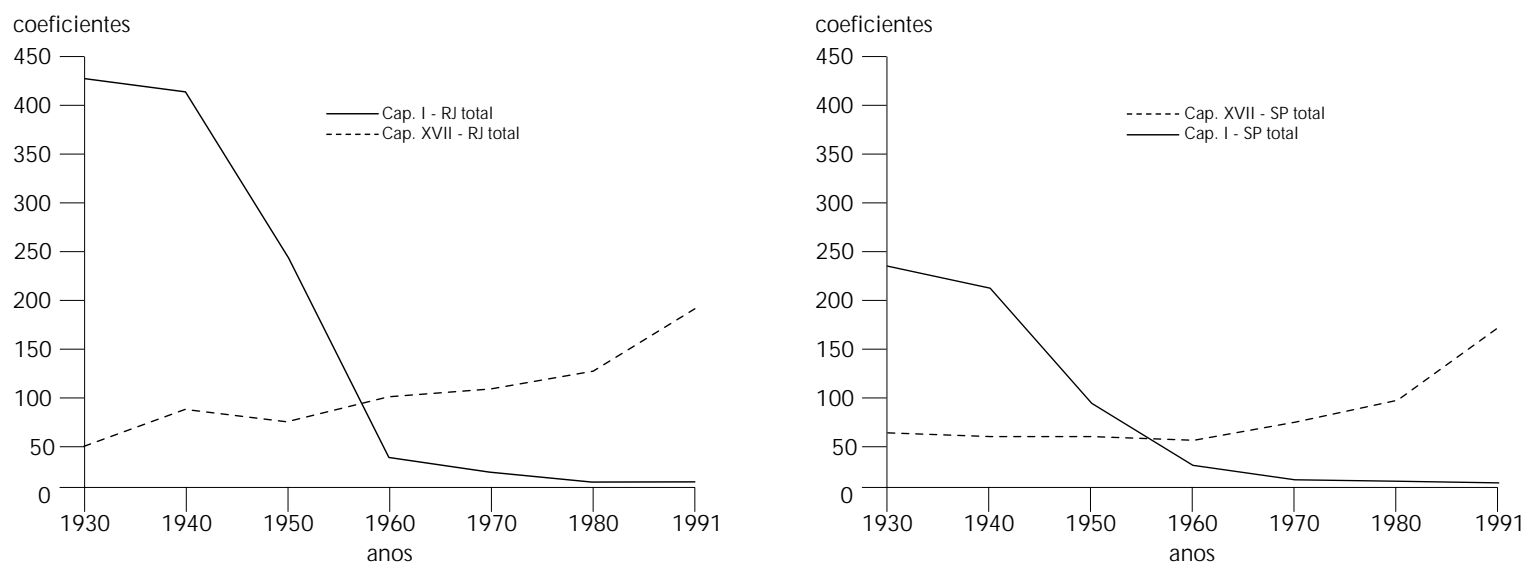

Figuras 3 e 4 - Coeficientes* de mortalidade, por doenças infecciosas e parasitárias e causas externas, faixa etária de 15 a 24 anos, Municípios do Rio de Janeiro e São Paulo, 1930-1991.
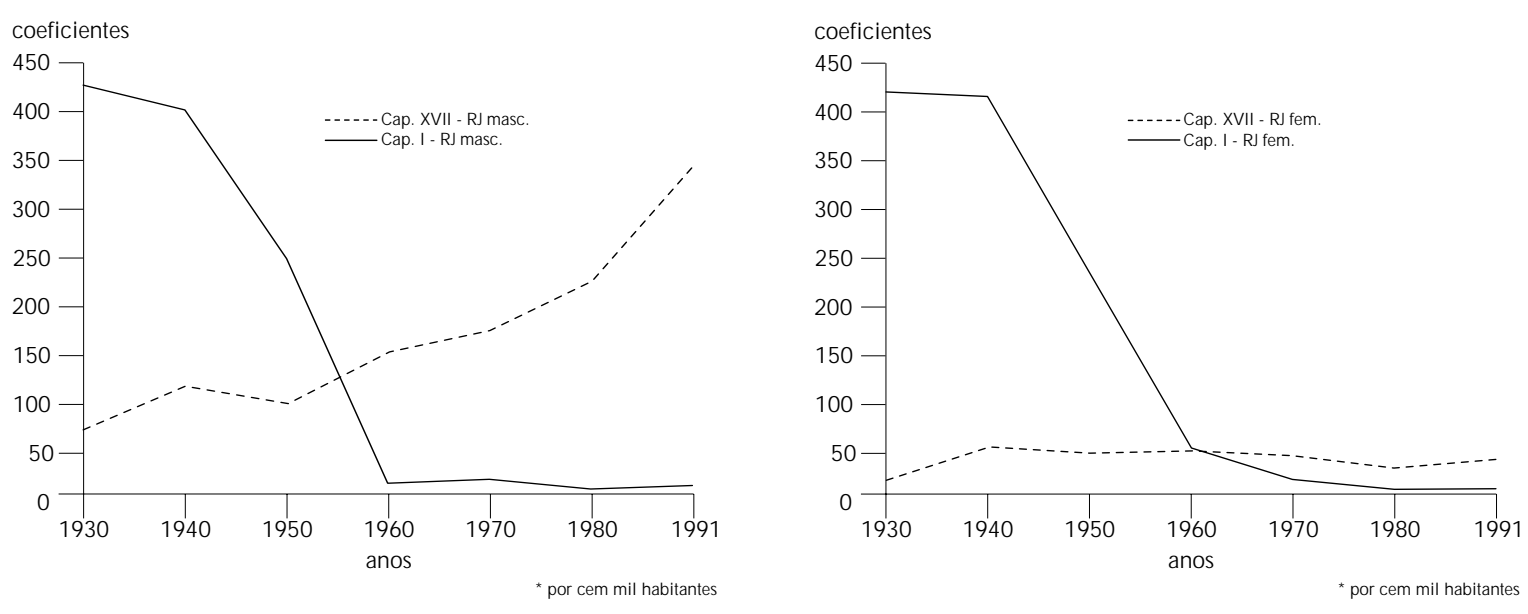

Figuras 5 e 6 - Coeficientes de mortalidade*, por doenças infecciosas e parasitárias e causas externas e por sexo, faixa etária de 15 a 24 anos, Município do Rio de Janeiro, 1930-1991.
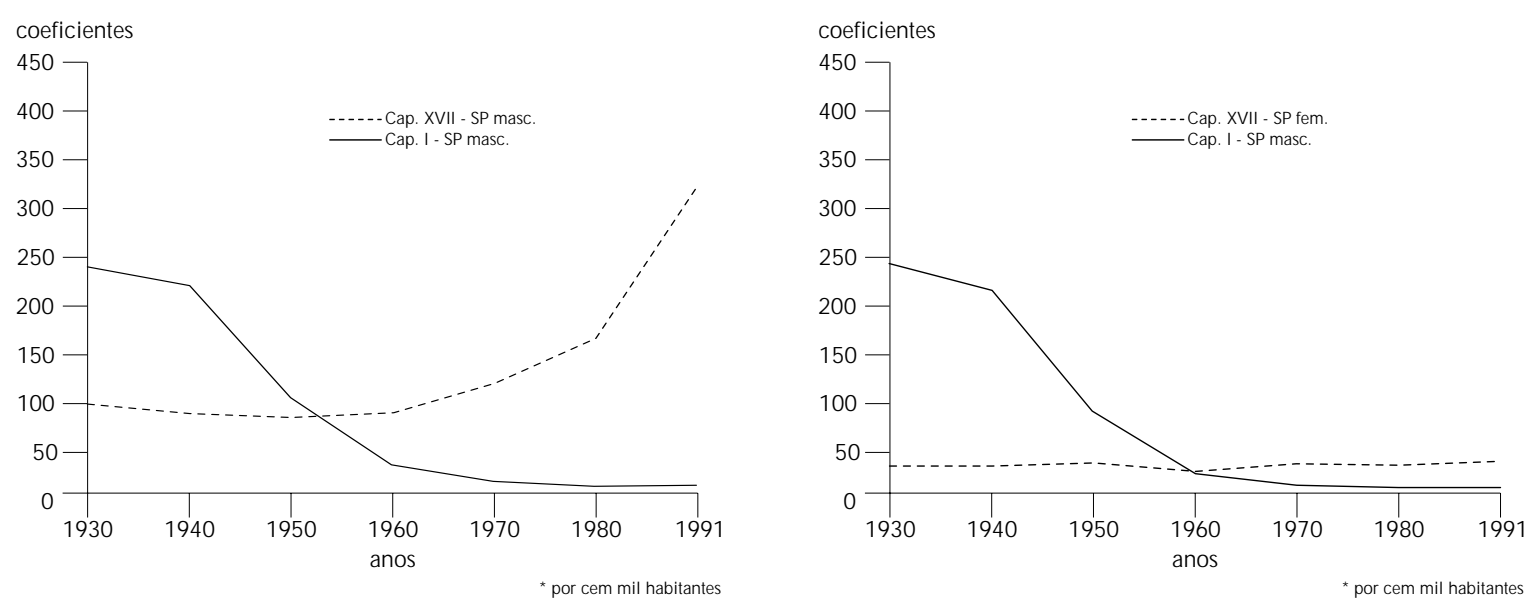

Figuras 7 e 8 - Coeficientes* de mortalidade por doenças infecciosas e parasitárias e causas externas e por sexo, faixa etária de 15 a 24 anos, Município de São Paulo, 1930-1991. 
riféricas, embora também desprovidos de infra-estrutura $^{12}$. Isto não significa que a situação sanitária de São Paulo fosse mais adequada, só é possível afirmar que era menos inóspita, pois a mortalidade pelas DIP, nesses primeiros períodos do século XX, era também muito elevada ${ }^{8}$.

Ao que tudo indica, as condições de insalubridade da cidade do Rio de Janeiro, do começo do século, tendo como elemento coadjuvante a metodologia de urbanização da cidade, traçou um perfil mórbido mais agudo, que associado, evidentemente, às crises econômicas sucessivas por que passou aquela coletividade, fez com que as medidas de controle aplicadas à Capital do Império não tivessem impacto tão rápido e bem-sucedido, a não ser as de controle vacinal obrigatório. A partir da transição das DIP para as violências, esta composição também foi responsável pelo novo quadro social.

Com a transição, o novo perfil de mortalidade colocou em destaque os acidentes de trânsito de veículo a motor, que, a partir de 1960 , momento da implantação da indústria automobilística, se tornaram responsáveis pela quase totalidade dos óbitos por acidentes de transporte (as causas acidentais mais freqüentes) no Rio de Janeiro e São Paulo. Os acidentes de transporte constituem-se percentual importante de todas as violências. Os jovens de São Paulo, principalmente, passaram a exibir elevadas taxas de mortalidade por acidentes de trânsito, associadas àquelas por homicídios.

Os homicídios, entre todas as violências e nos últimos anos, foram os que apresentaram as maiores taxas de mortalidade, sempre ascendentes nas duas cidades. As taxas de mortalidade por violências em geral, para o sexo masculino, no Rio de Janeiro, foram maiores do que as de São Paulo. Entretanto, contrariamente ao que vinha sendo observado, elas tiveram um aumento percentual duas vezes maior em São Paulo, no período de 1980 a 1991. Isto aproximou bastante as duas taxas. Os homicídios evidenciam aspectos dos mais negativos das mudanças de perfil, para o sexo masculino, embora os óbitos por violências não sejam exclusividade deste sexo. Por outro lado, o grande declínio dos óbitos por causas maternas exemplifica bem os aspectos positivos da transição para o sexo feminino.

Agrava a situação da mortalidade por causas externas, a grave crise no setor da saúde pública, de proporções ainda não adequadamente mensuradas, que vem colocando em risco os avanços obtidos. Os agravos atuais à saúde dos jovens, as violências, na maioria das vezes nem requerem assistência médi- ca, é bem verdade, já que os indivíduos não sobrevivem para recebê-la. Entretanto, existe uma parcela importante que só sobrevive às custas do funcionamento adequado dos serviços de emergência do setor público.

A violência nas duas cidades, em especial os homicídios, apresentam um amplo espectro de determinantes sociais, econômicos, culturais, já amplamente conhecidos. Não cabe aqui retomá-los. Entretanto, ao destacar os processos distintos de urbanização para as duas cidades, o que foi comentado na questão das DIP, cabe complementar que, também, o perfil de violências se apresenta com dupla face nesses diferentes contextos.

O processo de "favelização" da cidade do Rio de Janeiro, que definiu um perfil mais agudo para as DIP, também o fez para as violências. Não existem aí limites, dentro da geografia urbana, para a violência, ao contrário do que existe em São Paulo. Por isto, na primeira ela é mais explícita, "mora ao lado", enquanto na outra, por ser mais periférica, é mais velada. Associa-se a essas características, que contribuem para a peculiaridade do processo em cada uma das cidades, um quadro nacional de "pauperização", pela ausência de um projeto econômico que tenha por princípio a distribuição mais equânime da renda, além da não democratização e deterioração da justiça e da ética, em suas diferentes formas de expressão e execução.

Quanto às informações utilizadas no presente estudo, no que diz respeito à sua qualidade quanto às possíveis perdas, assinala-se que, por mais remotas que tenham sido as informações e mais discutíveis as metodologias utilizadas, tanto na coleta dos dados, quanto em sua organização, essas variações não seriam capazes de alterar as tendências observadas.

Para a superação de nossos padrões de saúde atuais é preciso desenvolver modelo próprio em que atuem categorias tais como condições de vida e de trabalho, com todas suas variáveis, e além de tudo avançar no conceito de "modo de vida do jovem brasileiro da atualidade", construído a partir dos revéses sociais e econômicos e conseqüiente degradação dos padrões familiares e, a partir daí, reformular inteiramente as propostas sanitárias existentes.

Em última análise, as epidemias de doenças infecciosas e parasitárias, no caso dos jovens, principalmente do sexo masculino, foram sendo substituídas, predominantemente pelas violências e, secundariamente, pela AIDS, o que determinou um novo padrão de mortalidade, que deve ser abordado segundo a multiplicidade de seus elementos. 


\section{REFERÊNCIAS BIBLIOGRÁFICAS}

1. ARAS, R. Teenage pregnancy: an epidemiological perspective. J. Fam. Welfare, 32: 65-74, 1986.

2. ARIÈS, P. História social da criança e da família. $2^{\mathrm{a}}$ ed. Rio de Janeiro, Zahar Editores, 1981.

3. BARRETO, M. L. et al. Mudanças dos padrões de morbimortalidade: uma revisão crítica das abordagens epidemiológicas. Physis, 3: 126-46, 1993.

4. BILAC, E. D. Famílias de trabalhadores: estratégias de sobrevivência. São Paulo, Símbolo, 1978.

5. BRAGA, J. C. S. \& PAULA, S. G. de. Saúde e previdência: estudos de política social. $2^{\text {a }}$ ed. São Paulo, Hucitec, 1986.

6. BRASIL. Lei $\mathrm{n}^{\circ} 8069$ de 13 de julho; dispõe sobre Estatuto da Criança e do Adolescente. In: Ministério da Saúde. Estatuto da criança e do adolescente. Brasília, 1991. p. 11.

7. BREILH, J. Epidemiologia: economia, política e saúde. São Paulo, Unesp/Hucitec, 1991.

8. COSTA, N. R. Lutas urbanas e controle sanitário: origens das políticas de saúde no Brasil. Rio de Janeiro, Vozes, 1986.

9. DECCA, M. A. G. Indústria, trabalho e cotidiano. Brasil 1889-1930, $4^{a}$ ed. São Paulo, Atual, 1991.

10. DUBY, G. Aux XII ${ }^{\mathrm{a}}$ siecles: les "jeunes" dans la societé aristocratique. In: Le Goff, J. $O$ maravilhoso e o cotidiano no ociente medieval. Lisboa, Edições 70, 1985. p. 67.

11. ENGEL, M. Meretrizes e doutores: saber médico e prostituição no Rio de Janeiro, 1840-1890. São Paulo, Brasiliense, 1989.

12. ESTRATÉGIA da elite garante a posição de hegemonia de São Paulo. O Estado de São Paulo, $1^{\circ}$ caderno, 31 ago, p. 5, 1993.

13. FUNDAÇÃO IBGE. Perfil estatístico de crianças e mães no Brasil: sistema de acompanhamento da situação socioeconômica de crianças e adolescentes, 1987, Rio de Janeiro, 1990.

14. GERONIMUS, A. T. Teenage maternity and neonatal mortality: a new look at American patterns and their implications for developing countries. Cambridge, Massachussets, Harvard University, 1986. (Center for Population Studies Discussion Paper N ${ }^{\circ} 87-3$ ),

15. LAURENTI, R. et al. Estatísticas de Saúde. São Paulo, EPU/EDUSP, 1985.

16. LAURENTI, R. et al. Mortalidade de mulheres em idade fértil no Município de São Paulo (Brasil), 1986. I Metodologia e resultados gerais. Rev. Saúde Pública, 24: 128-33, 1990.

17. LEVINE, M. D. \& McANARNEY, E. R. Early adolescents transitions. Lexington, Massachussets Lexington Books, 1988.
18. LINARES, M. A. M. de et al. Salud del adolescente. In: Congreso Venezoelano de Salud Publica, $7^{\circ}$, Caracas, 1986. Anais. Caracas, Ministerio de Sanidad y Assistencia Social, v. 4, 1986. p. 1922-2004

19. MARTINE, G. \& GARCIA, R. C. Os impactos sociais da modernização agrícola. São Paulo, Caetes/Hucitec, 1987.

20. MARTINE, G. As migrações de origem rural no Brasil: uma perspectiva histórica. In: Nadalin, S.O. et al. História e população: estudos sobre a América Latina. São Paulo, FSEADE, 1990. p. 16-25.

21. McANARNEY, E. R. Young maternal age and adverse neonatal outcome. Am. J. Dis. Child., 141: 1053-9, 1987.

22. McKEOWN, T. \& LOWE, C. R. An introduction to social medicine. 3rd. ed. Oxford, Blackwell Scientific, 1984.

23. MELLO JORGE, M. H. P. Estudo epidemiológico da mortalidade de adolescentes na Região das Américas. São Paulo, 1990 (Relatório enviado a OPS/OMS — contrato AM/MCP/MCH/010/P3/90-91/040) [Mimeografado].

24. MINAYO, M. C. \& SOUZA E. R. Violência para todos. Cad. Saúde Pública, 9: 65-78, 1993.

25. MINISTÉRIO DA SAÚDE. Divisão Nacional de Epidemiologia. Lista brasileira para mortalidade. Brasília, Centro de Documentação, 1987. (série G: Estatística e Informação em Saúde, 12).

26. MORTALIDADE nas capitais brasileiras 1930-1980, 1984. Dados Radis (ago.) 1984.

27. ORGANIZAÇÃO MUNDIAL DA SAÚDE. Manual $d a$ classificação estatística internacional de doenças, lesões e causas de óbito: Classificação Internacional de Doenças; $9^{-}$ Revisão - 1975, São Paulo, Centro da OMS para a Classificação de Doenças em Português, 1979. 2. v.

28. ORGANIZACION PANAMERICANA DE LA SALUD. La salud del adolescente y el joven en las Américas. Washington D. C., 1985 (OPAS - Public. Cient. 489).

29. ORGANIZACION PANAMERICANA DE LA SALUD. Las condiciones de salud en las Américas. 1981-1984. Washington D. C., 1986 (OPAS - Public. Cient. 500).

30. ORGANIZACION PANAMERICANA DE LA SALUD. Feundidad en la adolescencia: causas, riesgos y opciones. Washington, 1988 (OPS - Cuaderno Técnico, 12).

31. ORGANIZACION PANAMERICANA DE LA SALUD Las condiciones de salud en las Américas. Washington D. C. 1990 v. 1 (OPAS - Public. Cient. 524).

32. PANEQUE, R. J. La mortalidad del adulto de 15 a 49 anõs en Cuba, niveles y evolucion: 1960-1982. Rev. Cub. Adm. Salud, 12: 339-49, 1986.

33. SAWYER, D. R. T. O. Mortality-fertility relationship through historical socio-economic changes: the case of São Paulo, Brazil, 1980. [Tese de Doutorado - University of Harvard]. 
34. SILVA, F. A. \& ASSIS, P. I. História do Brasil. $2^{\mathrm{a}}$ ed. São Paulo, Moderna, 1988.

35. SIQUEIRA, A. A. F. \& TANAKA, A. C. d'A. Mortalidade na adolescência com especial referência à mortalidade materna, Brasil, 1980, Rev. Saúde Pública, 20: 274-9, 1986.

36. UNITED NATIONS. Latin America: demographic indicators of the adolescent population, 1960-2000. Chile, CELADE, 1985.
37. YAZAKI, L. M. \& ORTIZ, L. P. A questão da mortalidade: mortalidade infanto-juvenil. In: Fundação SEADE. O Jovem na Grande São Paulo. São Paulo, 1988. p. 151-77.

38. YUNES, J. Os níveis de saúde na região da Grande São Paulo. Rev. Saúde Pública, 4: 167-88, 1970.

39. ZALUAR, A. Teleguiados e chefes: juventude e crime. Religião e Soc., 15: 54-67, 1990. 